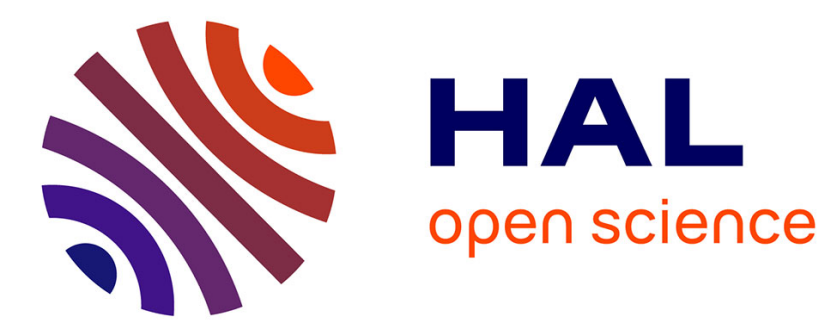

\title{
Local Lattice Structure Around Impurity Ions in IIa-VIb Compounds of NaCl Structure
}

\author{
T. Murata, S. Emura, H. Maeda, N. Yamashita, M. Nomura
}

\section{To cite this version:}

T. Murata, S. Emura, H. Maeda, N. Yamashita, M. Nomura. Local Lattice Structure Around Impurity Ions in IIa-VIb Compounds of NaCl Structure. Journal de Physique IV Proceedings, 1997, 7 (C2), pp.C2-1227-C2-1228. 10.1051/jp4:19972206 . jpa-00255278

\section{HAL Id: jpa-00255278 https://hal.science/jpa-00255278}

Submitted on 1 Jan 1997

HAL is a multi-disciplinary open access archive for the deposit and dissemination of scientific research documents, whether they are published or not. The documents may come from teaching and research institutions in France or abroad, or from public or private research centers.
L'archive ouverte pluridisciplinaire HAL, est destinée au dépôt et à la diffusion de documents scientifiques de niveau recherche, publiés ou non, émanant des établissements d'enseignement et de recherche français ou étrangers, des laboratoires publics ou privés. 


\title{
Local Lattice Structure Around Impurity Ions in IIa-VIb Compounds of NaCl Structure
}

\author{
T. Murata, S. Emura*, H. Maeda**, N. Yamashita*** and M. Nomura**** \\ Department of Physics, Kyoto University of Education, Fukakusa, Fushimi, Kyoto 612, Japan \\ * Institute of Scientific and Industrial Research, Osaka University, Ibaraki 567, Japan \\ ** Department of Chemistry, Faculty of Science, Okayama University, Okayama 700, Japan \\ *** Department of Physics, Faculty of Education, Okayama University, Okayama 700, Japan \\ **** Photon Factory, KEK, Tsukuba 305, Japan
}

\begin{abstract}
Results of fluorescence XAFS measurements for $\mathrm{Mn}$ in SrS and $\mathrm{Pb}$ in $\mathrm{CaS}$ as well as the absorption spectra of MnS and $\mathrm{PbS}$ are reported. The evidence of the similarity of the local structure around $\mathrm{Pb}$ ions in $\mathrm{CaS}$ and that of pure $\mathrm{PbS}$ is clearly shown by the analysis of the XAFS spectra. However, the structure around $\mathrm{Mn}$ ions in SrS is considerably deformed and not similar with that of $\mathrm{MnS}$. The results suggest that the local structure of the impurity ions is very much dependent on the difference of the size of impurity ions and that of the host ions.
\end{abstract}

\section{INTRODUCTION}

The Ila-VIb compounds activated with foreign metal ions are known as fluorescent materials for cathodoluminescence and electroluminescence. The impurity positive ions play a role of luminescent center of the material. When a guest ion is introduced into the host material, the impurity ion has been traditionally considered to be substituted with the ion of the host materials with maintaining the nearest neighbor distance of the host material. In the case of $\mathrm{CaS}: \mathrm{Pb}^{2+}$, for example, the distance between $\mathrm{Pb}$ and $\mathrm{S}$ is believed to be same as that of $\mathrm{Ca}$ and $\mathrm{S}$. The XAFS measurements revealed the feature of the local structure around the guest atom/ion in the host matrix. Mikkelsen and Boyce[1] first analyzed the local structure around the component atoms in GaAs-InAs, and observed a large discrepancy from the Vegard's law. However, the local structure around the impurity ions with small concentration such as the present cases is not well known yet. In order to understand the luminescence properties of these materials, it is important to obtain the information of the local structure around the luminescent center.

\section{EXPERIMENTAL}

Samples chosen are powder of $\mathrm{CaS}: \mathrm{Pb}^{2+}$ and $\mathrm{SrS}: \mathrm{Mn}^{2+}$. Both samples contain about 1 mole\% of impurity ions in the host. The former is the case of heavy impurity ions in the bulk with light cation, and the latter is the opposite case. Both of the host materials (CaS and $\mathrm{SrS}$ ) and sulfides of impurity ions (PbS and $\mathrm{MnS}$ ) crystallize into NaCl structure. Experiments were performed at the BL-7C XAFS station in the Photon Factory with Si(111) monochromator. Samples were cooled down to about $20 \mathrm{~K}$. Fluorescence XAFS measurements for $\mathrm{Pb} \mathrm{L}_{3}$ and $\mathrm{Mn} \mathrm{K}$ edge were done with using Lytle fluorescence detector. In order to improve the signal to noise ratio of the spectra, the dwell time for one point was set as 3 seconds, and measurements were repeated for 10 times. Absorption spectra were also measured for the $\mathrm{K}$ edge of the cations of the host materials of $\mathrm{CaS}$ and $\mathrm{SrS}$ and the sulfides of impurity cation, i.e. PbS and MnS. For the measuring Ca and Mn K-XAFS, a pair of quartz mirrors were used for the harmonic rejection.

\section{RESULTS AND DISCUSSION}

Data reduction process of the XAFS spectra is the standard one. In Figs. 1 and 2 are shown the $\chi(k)$ 's and their Fourier spectra for $k^{3}$-weighted $\chi(k)$ 's of the measured spectra. The spectra of $\mathrm{CaS}: \mathrm{Pb}$ and $\mathrm{SrS}: \mathrm{Mn}$ are not similar at all with those of $\mathrm{CaS}$ and $\mathrm{SrS}$. In the case of $\mathrm{CaS}: \mathrm{Pb}$ (Fig. 1) the Fourier spectrum shows that the local structure of around $\mathrm{Pb}$ impurity ions is similar to that of $\mathrm{PbS}$, since the positions of the Fourier peak of the first shell are similar with each other. The fitting calculation for the first shell of the $\mathrm{CaS}: \mathrm{Pb}$ was made using EXAFIT program [2]. Amplitude and phase functions were calculated using FEFF program [3]. During the fitting procedure, the first shell coordination number is fixed as 6 which is crystallographic value of $\mathrm{NaCl}$ structure in order to compare the Debye-Waller factor of $\mathrm{PbS}$ and $\mathrm{Pb}$ in $\mathrm{CaS}$.

Results are shown in Fig. 3 and obtained parameters are listed in Table 1. The discrepancy in the low $R$ region is due to the effect of the low frequency components of the Fourier spectrum. The $\sigma^{2}$ of the CaS:Pb is small compared with that of $\mathrm{PbS}$, which can be understood in the following way. The Ca-S distance of the host is $2.852 \AA$ at room temperature and is 
smaller than that of $\mathrm{PbS}$. Therefore, the lattice relaxation around the impurity ion induces expansion of the host lattice. This may cause the strong internal stress onto the $\mathrm{Pb}$ impurity ions, resulting in the smaller deviation of the first shell distance.

The results of $\mathrm{Mn}$ impurity in SrS are more complicated, as shown in Fig. 2. Both $\chi(k)$ 's and Fourier spectra are very different with each other. This suggests that the local structure around the Mn impurity ions in the host SrS is deformed and does not conserve the structure of the MnS. We could not get a reasonable fit for the first shell of the Fourier spectrum of the Mn impurity. The deformation around the $\mathrm{Mn}$ impurity ions in the host SrS may be very large due to the small size of the impurity ion comparing with the host $\mathrm{Sr}$ ion (3.005 $\AA$ between $\mathrm{Sr}$ and S, and $2.586 \AA$ between Mn and S). Therefore, Mn impurity ions have a large free space in the host lattice, and can be relaxed not at on-center position. More detailed analysis is necessary to have definite conclusion for this case.

Higher shell structures in the Fourier spectra of CaS:Pb and SrS:Mn were also analyzed with FEFF program. The results show that the lattice structure of matrix viewed from the impurity site is reflected in the Fourier spectra. The discussion is given elsewhere [4].
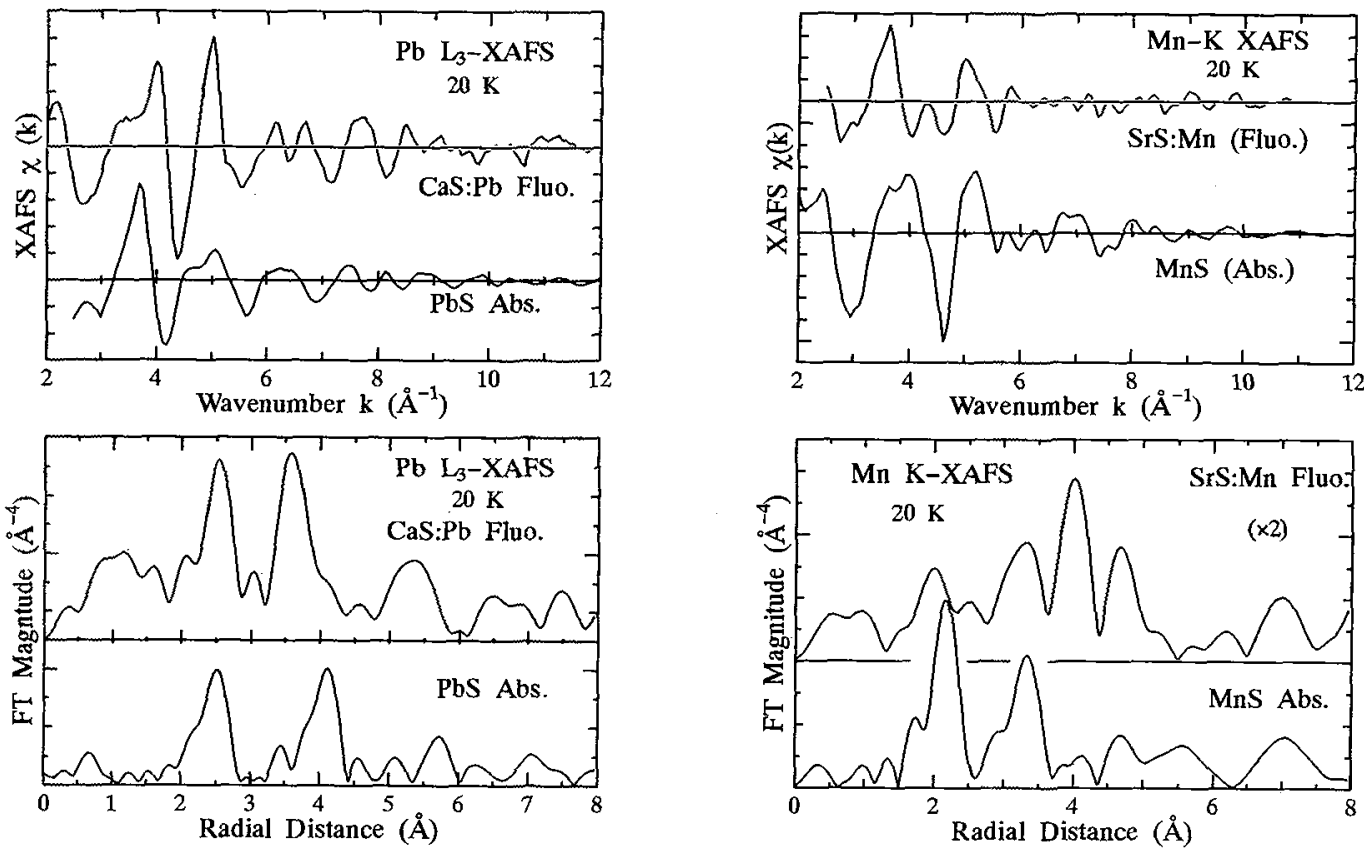

Figure 1: $\chi(k)$ and Fourier spectra of $k^{3}$-weighted $\chi(k)$ of $\mathrm{Pb} \mathrm{L}_{3^{-}}$ edge XAFS of $\mathrm{PbS}$ and $\mathrm{CaS}: \mathrm{Pb}$ measured at $20 \mathrm{~K}$.

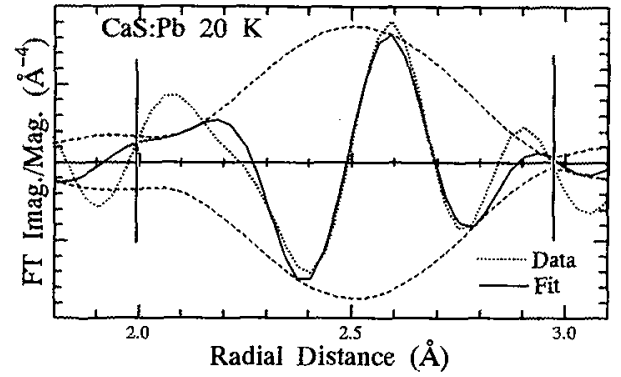

Figure 2: $\chi(k)$ and Fourier spectra of $k^{3}$-weighted $\chi(k)$ of Mn K edge XAFS of MnS and SrS:Mn measured at $20 \mathrm{~K}$.

Table 1: First shell distance $R$ and Debye-Waller factor $\sigma^{2}$ obtained from fitting calculation.

\begin{tabular}{ccc} 
Material & $R(\AA)$ & $\sigma^{2}\left(\times 10^{-2} \AA^{2}\right)$ \\
\hline $\mathrm{PbS}$ & $2.95 \pm 0.01$ & $0.86 \pm 0.05$ \\
$\mathrm{CaS}: \mathrm{Pb}$ & $2.94 \pm 0.01$ & $0.49 \pm 0.04$
\end{tabular}

Figure 3: R-space fit of first shell of Fourier spectrum of $\mathrm{CaS}: \mathrm{Pb}$.

\section{Acknowledgments}

This work has been performed with support from the photon Factory, through Proposal No. 91-032.

\section{References}

[1] Mikkelsen Jr, J. C., Boyce J. B., Phys. Rev. 28 (1983) 7130 -

[2] Bauchspiess K. R., Jpn. J. Appl. Phys. 32 (1993) Suppl. 32-2 131-133.

[3] Rehr J. J., Albers R.C.., Zabinsky S. I., Phys. Rev. Letters 69 (1992) 3397-3400.

[4] Murata T., Vol. 1 of the conference proceedings. 